\title{
Confirmation of the Sex Difference in Continuing Subperiosteal Apposition
}

\author{
STANLEY M. GARN, A. ROBERTO FRISANCHO, SAM T. SANDUSKY \\ AND MARY B. MCCANN \\ Center for Human Growth and Development, The University of Michigan, \\ Ann Arbor, and Center for Disease Control, Atlanta, Georgia
}

\author{
KEY WORDS Bone - Expansion ' Age $\cdot$ Changes $\cdot$ Sex $\cdot$ Bone \\ Gain - Bone Loss · Compensation.
}

\begin{abstract}
A major sex difference in the rate of continuing bone expansion was confirmed for 5660 adult subjects of European ancestry. The five-decade gain in metacarpal midshaft area amounted to $8.4 \%$ in 3455 females and $2.8 \%$ in 2205 males. There was no systematic age effect on the length of the second metacarpal. Accordingly, both bone expansion and the marked sex difference in its magnitude may be attributed to sex-specific aspects of ageing much like the sex difference in endosteal surface loss.
\end{abstract}

Continuing subperiosteal apposition during adult life is now a well-documented ageing phenomenon. First reported for the femur by Smith and Walker (64) and then for the rib section (Epker, Kelin and Frost, '65), adult bone "expansion" has since been shown for the second metacarpal (Garn et al., '67, '68) and for other tubular bones (Garn, '70). A similar gain in outer bony dimensions has also been demonstrated for the skull (Israel, '67, '71). Apparently, continuing bone expansion is both absolutely and relatively greater for the female (cf. Garn et al., '68; Garn, '70). If this sex difference can be confirmed, it indicates that the sexes differ as systematically in adult subperiosteal gain as in adult endosteal loss, and hence in the pattern of adult remodeling at both bone surfaces.

In the present study, we have made use of postero-anterior hand-wrist radiographs of a total of 5660 adult participants in the Ten-State Nutrition Survey of 1968-1970. There were 2205 males and 3455 females, all of European ancestry. Measurements of the total subperiosteal diameter $(\mathrm{T})$ and medullary cavity width (M) of the second metacarpal at midshaft were made with the $0.05 \mathrm{~mm}$ readout Helios calipers. These two diameters were computer-converted into total subperiosteal area $\left(0.785 \mathrm{~T}^{2}\right)$ and medullary cavity area $\left(0.785 \mathrm{M}^{2}\right)$ as described in
Garn ('70) and Garn, Poznanski and Nagy (71). The length of the second metacarpal (L) was also measured, as described. For uniformity with our several earlier publications on continuing metacarpal expansion, the total age range encompassed (25-84.9) was split into two three-decade groups, i.e., 25-54.9 and 55-84.9 with "midpoint" ages of 40 and 70 years, respectively (cf. Garn et al., '67, '68). In the present study there were not less than 858 subjects in any such three-decade age group.

As shown in the first table (table 1), there is clear evidence of an age-associated gain in total subperiosteal area (TA) at midshaft in both sexes. Comparing the two three-decade groupings, for each sex, the subperiosteal increase from midpoint age 40 to midpoint age 70 was $1.2 \mathrm{~mm}^{2}$ in males and $2.6 \mathrm{~mm}^{2}$ in females. Expressing these values on the basis of a five-decade period, apparent subperiosteal surface apposition amounted to $2.8 \%$ in males and $8.4 \%$ in females. These latter values are remarkably close to those previously observed for Central American and other populations where increases, expressed on a five-decade basis, equalled $2.9 \%$ for males and $8.6 \%$ for females, respectively (cf. Garn et al., '68, table 2).

Since the total period of continuing subperiosteal surface apposition considered in this study and encompassing the 
TABLE 1

Expansion of total subperiosteal area in 5660 adults of European ancestry

\begin{tabular}{|c|c|c|c|c|c|c|c|c|c|c|}
\hline \multirow{3}{*}{ Sex } & \multicolumn{6}{|c|}{ Total subperiosteal area (TA) as $\mathrm{mm}^{2}$} & \multirow{3}{*}{$\underset{\left(\mathbf{m m}^{2}\right)}{\mathbf{d}}$} & \multirow[b]{3}{*}{$z$ * } & \multirow{2}{*}{\multicolumn{2}{|c|}{$\begin{array}{c}\text { Five-decade } \\
\text { gain } 1\end{array}$}} \\
\hline & \multicolumn{3}{|c|}{ Age $25.0-54.9$} & \multicolumn{3}{|c|}{ Age $55.0-84.9$} & & & & \\
\hline & $\mathbf{N}$ & Mean & S.D. & $\mathbf{N}$ & Mean & S.D. & & & $\mathrm{mm}^{2}$ & $\%$ \\
\hline Males & 1347 & 70.5 & 11.7 & 858 & 71.7 & 12.6 & 1.2 & $2.2 * *$ & 2.0 & 2.8 \\
\hline Females & 2205 & 51.2 & 8.4 & 1250 & 53.8 & 8.9 & 2.6 & $8.4 * *$ & 4.3 & 8.4 \\
\hline
\end{tabular}

' Expressed as $5 / 3$ the three-decade gain, for uniformity with Garn et al. ('67, '68). Values from the regression of TA on age yield essentially similar results.

* Dividing the difference by the standard error of the difference, using table B in Guilford ('65).

* $p<0.05$.

$* * \mathbf{p}<0.0001$

twenty-fifth through the eighty-fifth year, respectively, includes the period of endosteal surface resorption that ordinarily begins by the fortieth year, it was useful to compare the amount of bone gained at the outer surface with the amount of bone lost at the inner (i.e., endosteal) surface in subjects of both sexes. This was done by projecting subperiosteal surface gain, expressed as square millimeters over the age range considered and similarly projecting bone lost at the endosteal surface over the same period of time. For the male, as shown in table 2 , bone gained subperiosteally over five decades amounted to $2 \mathrm{~mm}^{2}$ or $27 \%$ of the bone lost at the endosteal surface (i.e., $7.5 \mathrm{~mm}^{2}$ ). For the female, in turn, the subperiosteal surface gain of $4.3 \mathrm{~mm}^{2}$ was $39 \%$ of the $10.9 \mathrm{~mm}^{2}$ of bone lost at the endosteal surface. In both sexes, therefore, long-term subperiosteal gain, though numerically small, is relatively large compared with bone lost at the endosteal surface, during the same time period. Subperiosteal surface gain would appear to constitute a compensating effect on biomechanical properties.
Trotter and her associates (Trotter and Peterson, '67; Trotter, Peterson and Wette, '68) agree on the existence of age-associated dimensional changes such as these but suggest that the true explanation is a form of secular trend involving progressively longer but thinner bones in subjects of more recent birth. We have tested this possibility in the present data, and find that older males (aged 55-84.9) are significantly shorter in total length of the second metacarpal than those in the third, fourth and fifth decades, with a value of $t$ or $z$ equal to 4.0. On the other hand, the length of the second metacarpal is not significantly shorter in the women aged 55-84.9 and is, in fact, slightly longer $(64.0 \mathrm{~mm})$ than those of the younger age grouping $(63.9 \mathrm{~mm})$. Accordingly, the phenomenon of continuing bone expansion, clearly of greater magnitude in the female than in the male, cannot be explained on a secular basis in the present data. Since we have earlier demonstrated continuing bone expansion on a cross-sectional basis as has Israel, both in his earlier studies and in his recent doctoral thesis (Israel, '67, '71) we

TABLE 2

Long-term subperiosteal gain compared with long-term endosteal loss in adult males and females

\begin{tabular}{|c|c|c|c|c|}
\hline \multirow[b]{2}{*}{$\operatorname{Sex}$} & \multicolumn{2}{|c|}{ Five-decade } & \multirow[b]{2}{*}{$\begin{array}{l}\text { Net bone } \\
\text { loss }\end{array}$} & \multirow{2}{*}{$\begin{array}{c}\text { Gain as } \\
\text { percent } \\
\text { of loss }\end{array}$} \\
\hline & $\begin{array}{l}\text { Subperiosteal } \\
\text { surface gain }\end{array}$ & $\begin{array}{c}\text { Endosteal } \\
\text { surface loss } 2\end{array}$ & & \\
\hline Males & $\begin{array}{c}m m^{2} \\
2.0\end{array}$ & $\begin{array}{r}m m^{2} \\
7.5\end{array}$ & $\begin{array}{c}m m^{2} \\
5.5\end{array}$ & 27 \\
\hline Females & 4.3 & 10.9 & 6.6 & 39 \\
\hline
\end{tabular}

1 From table 1.

2 Similarly calculated from values of medullary area (MA) for the same subject groupings. 
believe that continuing bone expansion is a true ageing effect.

Earlier writers, among them Smith and Walker (64), have interpreted the evidence for continuing bone expansion as indicating a response either to compression stress (as in major weight-bearing bones) or to flexion stress (as for the rib). The inclusion of the second metacarpal and the several bones of the skull now make the weight-bearing hypothesis unlikely, and both also question the notion that continuing subperiosteal apposition is a simple response to flexion stress. Again, while the period of adult bone resorption (beginning at about age 40) is included within the age span described in this study, all the evidence appears to indicate a linear trend for subperiosteal bone gain, continuing from the third through the eighth decade, whereas the phenomenon of adult endosteal surface resorption begins toward the end of the fourth decade and then exhibits a hyperbolic relationship with advancing age. Under these circumstances, it is not logical to view the linear trend of subperiosteal apposition with its much earlier age of onset as a functional response to the curvilinear trend of endosteal resorption with its much later age of beginning occurrence.

Up to now there is no simple explanation for the greater magnitude of continuing subperiosteal apposition in the female, whether we include only the 5660 subjects from the present study or an additional 4924 subjects in our two earlier publications. The uniformity is there, and the magnitudes of gain closely agree, in the disparate samples, but there is no obvious nutritional or occupational explanation. There is, of course, the very fortunate correspondence with the behavior of the skull, both on a cross-sectional and a longitudinal basis (cf. Israel, '67, '71). In the expansion with age and with respect to sex, round, long and flat bones behave alike.

Probably the most important point to observe is the marked sex difference in rates of adult bone remodeling at both bone surfaces. The female differs from the male in endosteal surface resorption, losing more bone absolutely after the fifth decade and approximately twice as much bone on a relative or percentage basis. The data from these 5660 adult Americans as well as the data from 4924 subjects from eight populations combine to indicate that the female similarly exceeds the male in both absolute and relative rates of subperiosteal surface expansion and in the extent to which outer bone gain represents a partial mechanical compensation for inner bone loss.

\section{ACKNOWLEDGMENTS}

The work described in this paper was carried out under Contract HSM 110-6922 , many of the calculations were completed by Jerrold M. Nagy, the manuscript was completed by Shirley M. Garrett, and Professor J. E. Milholland was most helpful in suggesting appropriate tests of significance for the difference between largesample N's with unequal variances. We appreciate the assistance of $\mathrm{Mr}$. Richard L. Miller of the computation facility of the Center for Human Growth and Development.

\section{LITERATURE CITED}

Epker, B. N., M. Kelin and H. M. Frost 1965 Magnitude and location of cortical bone loss in human rib with aging. Clin. Orthop., 41 . 198-203.

Garn, S. M. 1970 The Earlier Gain and the Later Loss of Cortical Bone: In Nutritional Perspective. Charles C Thomas, Springfield, Il linois.

Garn, S. M., A. K. Poznanski and J. M. Nagy 1971 Bone measurement in the differential diagnosis of osteopenia and osteoporosis. Radiol., 100: 509-518.

Garn, S. M., C. G. Rohmann, B. Wagner and W. Ascoli 1967 Continuing bone growth throughout life: A general phenomenon. Am. J. Phys. Anthrop., 26:313-317.

Garn, S. M., B. Wagner, C. G. Rohmann and W. Ascoli 1968 Further evidence for continuing bone expansion. Am. J. Phys. Anthrop. 28: $219-221$

Guilford, J. P. 1965 Fundamental Statistics in Psychology and Education. McGraw-Hill, New York.

Israel, H., III 1967 Continuing growth in the human cranial skeleton. Arch. Oral Biol., 13. 133-138.

1971 The Impact of Aging upon the Adult Craniofacial Skeleton. Ph.D. Thesis. University of Alabama, Birmingham.

Smith, R. W., Jr., and R. R. Walker 1964 Femoral expansion in aging women: Implications for osteoporosis and fractures. Science, 145: 156-157. 
Trotter, M., and R. R. Peterson 1967 Transverse diameter of the femur: On roentgenograms and on bones. Clin. Orthop., 52: 233239.
Trotter, M., R. R. Peterson and R. Wette 1968 The secular trend in the diameter of the femur of American Whites and Negroes. Am. J. Phys. Anthrop., 28: 65-74. 